\title{
"Escolhe uma palavra e diz alguma coisa": reflexões sobre a apresentação dos cursos de licenciatura em artes visuais no espaço das profissões da UFG ${ }^{1}$
}

\author{
Irene Tourinho ${ }^{2}$ \\ Aurisberg Leite Matutino ${ }^{3}$ \\ Fernanda Moraes Assis ${ }^{4}$ \\ Gabriel Moraes de Queiroz ${ }^{5}$ \\ Júlia Mariano Ferreira ${ }^{6}$ \\ Maurício Remigio Viana ${ }^{7}$ \\ Rogério Justino Flori ${ }^{8}$ \\ Tales Gubes Vaz ${ }^{9}$ \\ Vandimar Marques Damas ${ }^{10}$
}

\section{Resumo}

Este texto é escrito por várias mãos e apresenta-se não apenas como um desafio intelectual: é também uma provocação de sociabilidade. A partir de distintos olhares, refletimos sobre o evento Espaço das Profissões, observando e examinando os ambientes dedicados à Licenciatura em Artes Visuais nas modalidades presencial e a distancia, propondo uma discussão a respeito de suas implicações sobre nós, mestrandos em Arte e Cultura Visual, na condição de visitantes. Apontamos algumas dessas impressões destacando alguns pontos, tais como os imaginários da docência e o fazer na prática pedagógica contemporânea no ensino de arte, estas, julgamos ser posições que se orientam a partir das discussões realizadas na disciplina Tópicos Especiais em Educação Visual, no PPGACV da Faculdade de Artes Visuais (FAV) da UFG.

Palavras-chave: experiência coletiva, docência, prática pedagógica e arte.

\section{Abstract}

This text is written by many hands and is presented not only as an intellectual challenge: it is also a provocation of sociability. From different perspectives, we reflected about the event "Professional Spaces", through which we observed and examined the environments dedicated to the Teacher Training Program in Visual Arts, including the distance learning

\footnotetext{
${ }^{1}$ Este artigo é o relato de uma experiência isolada, não de uma investigação em andamento. Suas questões se inter-relacionam com as pesquisas de cada um de seus participantes de diferentes maneiras.

2 Pós-Doutora em Cultura Visual pela Universidade de Barcelona (Espanha), Doutora pela Universidade de Wisconsin-Madison (EUA) e Mestre pela Universidade de Iowa (EUA). É Coordenadora do Programa de PósGraduação - Mestrado em Cultura Visual e Professora Titular da Faculdade de Artes Visuais da Universidade Federal de Goiás. É membro dos Grupos de Pesquisa GEPAEC (UFSM) e GPCVE (UFG) e associada da ANPAP, ANPED, INSEA e FAEB.

${ }^{3}$ Mestrando do Programa de Pós-Graduação em Arte e Cultura Visual (PPGACV) da Universidade Federal de Goiás (UFG), com especialização em Gestão de Marketing e Comunicação (MBA) e graduado em Artes Visuais com habilitação em Design Gráfico pela UFG.

${ }^{4}$ Licenciada em Artes Visuais pela UFG (2003). Coordena as atividades pedagógicas da equipe de artes visuais no Centro de Estudo e Pesquisa Ciranda da Arte, da Secretaria de Estado da Educação de Goiás (SEDUC).

${ }^{5}$ Especialista em Cultura e História Africana e Afro-Americana pela Universidade Estadual de Goiás (UEG) e licenciado em Artes Visuais pela UFG.

6 Pós-Graduada em Fotografia pela Universidade Estadual de Londrina (UEL) e em MBA - Gestão da Responsabilidade Socioambiental e do Terceiro Setor (ESUP). Graduada em Comunicação Social com habilitação em J ornalismo pela UFG. Fotógrafa e professora na Faculdade Alves Faria (ALFA) em Goiânia.

7 Mestrando do PPGACV da UFG. Especialista em Metodologia do Ensino da Arte e licenciado em Educação Artística. Professor de arte do ensino básico.

8 Mestrando do PPGACV da UFG, Especialista em Direção de Cinema pela Faculdade Cambury (2004) e graduado em Comunicação Visual pela UFG (1999).

${ }^{9}$ Mestrando do PPGACV da UFG, Especialista em Expressão Gráfica pela Pontifícia Universidade Católica do Rio Grande do Sul (PUCRS) e graduado em Comunicação Social com habilitação em Jornalismo pela Universidade Federal do Rio Grande do Sul (UFRGS).

10 Mestrando do PPGACV da UFG e graduado em Ciências Sociais. Tutor do ensino a distancia no curso de Licenciatura em Artes da UFG.
} 
modality. We propose a discussion about its implications to us as students of the Graduate Program in Art and Visual Culture, and as visitors of the event. We point out some of these impressions highlighting points, such as teaching imaginary and contemporary pedagogic practice in arts education, positions which are based on the discussions of the discipline Special Topics in Visual Education offered by the Graduate Program in Art and Visual Culture of the College of Visual Arts, UFG.

Keywords: collective experience, teaching, practice teaching and art.

\section{I ntrodução}

Este artigo nasce de um exercício realizado durante a disciplina Tópicos Especiais em Educação Visual, do Programa de Pós-Graduação em Arte e Cultura Visual, nível de mestrado, da Faculdade de Artes Visuais da UFG, ministrada pela Profa. Dra. Irene Tourinho. Este é um texto escrito por várias mãos e, portanto, a diversidade de pensamento e idéias encontrada nele é intencional. Nesse sentido, utilizamos a primeira pessoa do plural para construir o artigo, pois descrevemos experiências pessoais elaboradas como vivências de um grupo. Entretanto, ao elaborar essa escrita no plural, não temos a pretensão de reforçar um afastamento na relação entre sujeito e objeto ${ }^{11}$.

Os encontros do grupo para a produção deste texto revelaram a dificuldade de trabalhar coletivamente. Estabelecer parâmetros para a discussão e para a escrita, assim como chegar a consensos sobre o que deve ser incluído ou excluído, apresenta-se não apenas como um desafio intelectual, mas como uma provocação de sociabilidade. Somos colegas e temos algumas orientações semelhantes para nosso pensar. Porém, cada um de nós possui uma trajetória e, portanto, pontos de vista particulares. Em razão disso, outorgamo-nos o direito de, ao longo do texto, discordar de nós mesmos, oferecendo olhares distintos sobre um único tema, em lugar de expor certezas e consensos.

Durante essa aula, ocorrida em maio de 2010, em razão da movimentação causada pelo evento Espaço das Profissões, recebemos a orientação para circular pelas salas da FAV, observando e anotando a maneira como os cursos da unidade acadêmica se apresentavam/representavam para o público de alunos visitantes. A idéia era observar tanto a forma que cada "profissão"12 expõe suas concepções e práticas, como elas justificam-se social e academicamente na tentativa de atrair o interesse dos estudantes. Focamos nossa atenção na sala do Curso de Licenciatura em Artes Visuais, propondo uma discussão a respeito de suas implicações sobre nós, mestrandos, também na

\footnotetext{
11 Acreditamos que a utilização do pronome pessoal da terceira pessoa "nós" responde a uma postura acadêmica convencional de que as pesquisas sejam feitas de modo objetivo, minimizando a influência de opiniões e interesses dos pesquisadores. Vemos esse distanciamento como uma impossibilidade, de fato, que produza uma objetividade totalizante para a pesquisa, uma vez que a escolha de um tema para investigação já indica uma opção pessoal.

${ }_{12}$ A FAV oferece os seguintes cursos: Design de Moda, Design de Interiores, Design Gráfico, Arquitetura, Bacharelado e Licenciatura em Artes Visuais.
} 
condição de visitantes, assim como focalizamos um certo cuidado pelas imagens e ideias selecionadas para representar a profissão docente.

\section{O espaço das profissões}

Desde a década de 1990, são realizados eventos para integrar a sociedade à universidade. Inicialmente, no âmbito do Programa "A Cidade vai à UFG", era montada uma tenda na Praça Universitária, próxima ao centro da cidade, no Campus I, que concentra uma pequena parcela dos cursos da UFG. Neste evento, os cursos expunham os trabalhos de extensão com o intuito de abrir as portas da universidade para que a população conhecesse o que era realizado na instituição. A partir de 2004, o projeto de integração passa a acontecer semanalmente, quando escolas de nível médio visitavam a universidade e eram recebidas pela Assessoria de Comunicação que acompanhava alunos e professores apresentando as unidades de ensino. Em cada unidade os docentes forneciam informações sobre os cursos.

A partir de 2009, tem início o projeto Espaço das Profissões ${ }^{13}$, cujo objetivo é aproximar a universidade dos estudantes de ensino médio, proporcionando um contato entre os profissionais e alunos da UFG com os estudantes visitantes. O evento acontece durante um dia de visitação aberta à UFG, no qual são realizadas palestras explicativas sobre os diferentes cursos e profissões oferecidos pela instituição. Cada curso dispõe de uma sala, onde são expostos trabalhos de alunos, cartazes com objetivos do curso, vídeos institucionais ou de projetos de disciplinas e exemplos de resultados de propostas práticas. Um grupo de professores e alunos de cada curso faz plantão na sala recebendo e dialogando com os estudantes.

Nossa análise, neste artigo, centra-se apenas nos espaços dedicados à Licenciatura em Artes Visuais, nas modalidades presencial e a distancia. Essa escolha orienta-se a partir do foco da disciplina Tópicos Especiais em Educação Visual, que examina relações entre processos educativos, construção de currículo e cultura visual. Não pretendemos, com este recorte, indicar que os demais cursos da FAV não tenham um caráter educativo ou aportes da cultura visual, pois todos os cursos, de alguma forma, utilizam imagens artísticas, de informação, gráficas e outras, para expor concepções que os orientam através de caminhos que constituem a formação que oferecem. Todos, de alguma maneira, "representam-se" por meio de imagens. Estas e as formas de exposição que os cursos utilizam podem convidar e atrair diferentes pessoas a se considerar membros de um grupo, já que nossos vínculos dão-se por intermédio de imagens, símbolos e ideias.

\footnotetext{
13 Esse projeto não é uma proposta exclusiva da UFG. Outras universidades do país, ainda que com outros
} nomes, também realizam iniciativas semelhantes. 
Assim, entendemos que a importância de debater os modos de representação do curso de licenciatura constitui parte significativa de sua proposta, formadora de docentes da área de artes, estabelecendo como eixo da formação a interação entre ensino, aprendizagem e visualidades.

\section{A exposição do curso de licenciatura em artes visuais - modalidade presencial} Inicialmente circulamos separadamente pelo Espaço das Profissões, colhendo impressões e conversando com participantes, monitores e professores, conforme as expectativas e dúvidas de cada um frente a cada curso. Ao reunirmo-nos para debater o que percebemos, notamos que algumas observações eram semelhantes, indicando pontos recorrentes que se destacavam em relação à maneira como o curso escolhia ser representado. Nossa discussão apontou, preliminarmente, para a ideia de que os cursos selecionavam estratégias para "vender sua imagem" aos possíveis futuros alunos. Questionamos a postura de comercialização do ensino vinculada a uma universidade pública, embora desconheçamos dados estatísticos que apontem para a existência de vagas ociosas. Essa postura de "loja oferecendo produtos" foi especialmente observada nos cursos ligados às formações em Design (Gráfico e de Moda), Arquitetura e Urbanismo e no Bacharelado em Artes Plásticas. Estes cursos validam-se de um apelo visual e gráfico bastante intenso, elaborados com recursos tecnológicos sofisticados e altamente atraentes. Imagem, som e movimento criavam estratégias de chamamento e sedução aos visitantes, futuros consumidores/produtores das práticas em questão.

Notamos que a licenciatura, em relação às demais áreas, apresentava-se de maneira pouco expressiva, fato que se refletia na ausência de interesse dos visitantes que entravam e saíam rapidamente da sala, poucas vezes interagindo com os professores presentes. Cada sala expositiva exibia, na entrada, banners explicativos e bem ilustrados, convidando os visitantes para entrar no espaço e conhecer a estrutura geral do curso, seus objetivos e possibilidades de atuação profissional. Contudo, o pôster exposto na entrada da sala do Curso de Licenciatura em Artes Visuais (presencial) apresentava poucos atrativos estéticos: além de não mostrar imagens, estava sobrecarregado com um texto impresso em fontes pequenas que dificultavam a leitura. Diante do excesso de informação textual, os visitantes desinteressavam-se pelo conteúdo do informativo.

Havia muitos desenhos e pinturas afixadas nas paredes, além de um telão onde eram projetadas imagens dos cursistas. Desenhos e pinturas realizados em papel sulfite, tamanhos A4 e A3, com lápis ou tinta, mostravam trabalhos de alunos organizados a 
partir de temas e disciplinas. Informações, também impressas em fontes bastante reduzidas, indicavam as técnicas, materiais, ementas e período das disciplinas na estrutura curricular. A voz dos licenciandos estava ausente...

No centro da sala, sobre um conjunto de mesas, havia um grande número de palavras escritas em pedaçinhos de papel, dispostos de forma aleatória. Segundo os professores responsáveis pela sala, tratava-se de uma atividade interativa, na qual os visitantes eram convidados a escolher um dos papéis e seguir a orientação dos monitores: "Você pega uma palavra e diz alguma coisa sobre ela". Estranhamos o jogo proposto, pois, em realidade, não acontecia uma interação. Os estudantes manifestavam suas idéias sobre a palavra escolhida e assim encerrava sua participação na atividade. Ficamos com a impressão de que o foco da atividade, em vez de privilegiar a elaboração de questionamentos, concentrava-se na expressão de possíveis respostas.

Ao mesmo tempo, havia incompatibilidade entre as características das palavras constantes da atividade, visto que apareciam conceitos, técnicas e nome de pesquisadores e professores. Assim, encontramos palavras tão diferentes como: gravura, artista, loucura, Paulo Freire, percepção, Ana Mae, desenho, Piaget, etc. A idéia de pensar sobre o quê uma palavra insinua ou alude pode provocar interação quando se refere a um conceito, mas o diálogo torna-se difícil em relação, por exemplo, à palavra "Piaget". Esta dificuldade pode ser vista como uma das explicações para a baixa participação e/ou interesse dos visitantes na atividade, conforme observamos.

Um projetor multimídia lançava, em uma tela branca, imagens dos estudantes do curso realizando algumas atividades, aparentemente em escolas nas quais desenvolvem estágios ou tarefas extracurriculares. No entanto, a maioria das imagens apresentava os alunos posando, relegando a um segundo plano as atividades ou o modo como eram trabalhadas nas aulas.

Encerramos a visita à sala, cada um em seu momento, mas com uma impressão compartilhada de que $\mathrm{o}$ espaço $\mathrm{e}$ as ações propostas poderiam ser melhores aproveitados e explorados. Não fomos cativados a experimentar possibilidades de interação e reflexão sobre o curso e o ensino de arte na contemporaneidade. Percebemos a dificuldade dos monitores (alunos de licenciatura) para abordar e lidar com os estudantes que visitavam aquela pequena sala. Que sentidos estariam sendo criados no imaginário dos alunos em contato com essas representações? Como poderiam ser expostas as experiências de licenciandos para mostrar tanto a unidade quanto a diversidade presente nas ações do Curso? 


\section{A exposição do curso de licenciatura em artes visuais - modalidade à distância (EAD)}

A apresentação do Curso de Licenciatura em Artes Visuais, na modalidade de ensino a distancia (EAD), reforçava uma preocupação em justificar o porquê de sua existência, deixando de ressaltar o posicionamento de ser esta uma proposta inovadora, democrática, em constante crescimento e transformação, conforme vem se caracterizando o referido curso.

Assim que entramos na sala - éramos um grupo, neste momento - ouvimos um dos professores esclarecer aos visitantes o que era o curso e de que modo ele funcionava. Apresentaram um vídeo sobre o curso - "verdades e mitos" -, onde alunos/atores informavam sobre sua experiência no curso. Um cartaz, colocado na parede interna da sala, explicava, através de perguntas e respostas, as dúvidas - certamente as mais freqüentes em relação ao curso. Perguntas como: "É caro?", "Faremos prova a distancia?" ou "Nosso diploma tem a mesma validade do curso presencial?" eram respondidas no cartaz. Os visitantes permaneciam sentados enquanto assistiam ao vídeo e à fala de uma docente.

O curso foi apresentado como uma proposta que privilegia uma nova relação professoraluno, na qual hierarquias são rompidas, pois o professor não é mais a principal referência e, em decorrência, o aluno deve desenvolver autonomia para buscar, por conta própria, informações e formas de conhecimentos. Nesta modalidade de ensino, segundo a apresentadora, o aluno já entraria no curso com a atitude de um pesquisador.

No entanto, a exposição tinha como referência central e permanente, os alunos e ações do curso presencial. Informações e explicações sempre eram dadas, tomando como referência o curso presencial. É inegável o avanço conceitual e prático da modalidade EAD e suas novas formas de ensino aprendizagem, especialmente nas formas de comunicação e no estabelecimento de vínculo entre professor e aluno. Porém, registramos a necessidade do desenvolvimento de referenciais teóricos específicos para que o curso pudesse ser apresentado e reconhecido em sua concepção diferenciada. Registramos ainda a necessidade de estratégias de interação entre os alunos das duas modalidades - presencial e a distancia, para que sejam implementadas maneiras ampliadas de diálogo. Essa comunicação evitaria o estreitamento da discussão para questões que se centram apenas nas vantagens e desvantagens das duas modalidades de formação. 
Uma pergunta feita por um dos professores da sala de EAD aos visitantes foi "Alguém aqui deseja ser professor?" O silêncio veio como resposta. Pensamos que a pergunta poderia ter outro eixo norteador: por exemplo, centrar-se na experiência de aprendizagem do aluno ou, talvez, na questão da autonomia que o ensino a distancia propõe e estimula.

Outra reflexão que fizemos diz respeito à possibilidade de que o discurso naquele ambiente pudesse ocupar-se de uma ética de ensino pautada não na disciplina ou na formação de profissionais para o mercado de trabalho, mas para formação de sujeito autônomos e capazes de provocar transformações nas práticas de relações de poder no cotidiano, seja da escola, do trabalho ou demais instâncias do espaço público.

Optamos por comentar a exposição da sala referente à modalidade a distancia, porém não aprofundamos a discussão a respeito de nossas impressões. Divergimos quanto a este tópico, por conta das diferenças que acreditamos existir entre docentes e alunos das duas modalidades, que não cabe a nós, dentro da proposta deste artigo, explorar.

\section{A representação do educador de artes no espaço das profissões}

Alguns companheiros deste artigo não são licenciados em artes visuais, ou seja, nossos pontos de vista não estão necessariamente conectados com o que se discute nos cursos de licenciatura em termos dos desafios e necessidades para a formação de professores. A partir da diversidade de formações que nos caracteriza, observamos o Espaço das Profissões com expectativas diferentes e, mesmo assim, algumas de nossas percepções mostraram-se bastante semelhantes. Ali estava em jogo a apresentação de caminhos e alternativas possíveis para uma geração de futuros alunos universitários que, através das formas como expunham suas orientações e práticas, tentavam conformar, neutralizar ou interromper estereotipias que configuram as maneiras como cada curso/profissão "representa-se".

Sem a pretensão de sermos assertivos ou elaborar respostas e fazer afirmações generalizantes, apontamos algumas das nossas impressões e destacamos alguns pontos que podem contribuir para o fortalecimento e consolidação deste Espaço de Profissões: os imaginários da docência, o "fazer" na prática pedagógica contemporânea e, finalmente, a produção de arte e modos de vida contemporânea. Estes pontos são reforçados pela idéia de Arroyo (2007, p. 11) que, paralelamente, instiga-nos e advertenos ao dizer que para "redefinir imaginários de alunos exige-se redefinir imaginários da docência e da pedagogia". 
Em nossas discussões, lembramos que a licenciatura em artes tem sido "representada" como um curso para "tias", senhoras cansadas dos afazeres domésticos em busca de algo para distrair-se, para aproximar-se da vida, como se o curso fosse uma espécie de terapia de grupo. Compreendemos que esta representação é falsa e carrega um estereótipo que estigmatizou esta formação, principalmente na primeira metade do século XX. Nossa visão, neste caso das "representações" dos cursos de licenciatura, é que o Espaço das Profissões deve enfatizar as transformações epistemológicas e conceituais da área e mostrar suas ressonâncias no sistema social, cultural e político, reforçando processos de reinvenção do ensino e intensificando o fato de que "o interessante hoje é pensar a arte enquanto instância crítica da realidade. Ela pretende ser algo que está no mundo, mas que critica os modos de agir e pensar desse mundo" (Conduru apud MARTINS; TOURINHO, 2005, p. 97).

Ser professor mostra-se como um desafio constante. Para assumir essa profissão, muitas vezes, exige-se, além de paixão, valentia e determinação. Ao longo da história, a sociedade foi construindo uma imagem filantrópica e romântica do professor. Tornam-se aparentes, nesta perspectiva estereotipada, formas de representação binárias deste profissional, especialmente no que se refere à sua prática, ora taxando-o de bom ou ruim, capaz ou incapaz. Para não cair na cilada desta lógica dualista, é importante que se busque compreender o processo de construção da imagem social do professor e sua identidade como algo móvel, relacional, em constante construção (HALL, 2000).

Esta questão pode ser vista a partir de, pelo menos, duas perspectivas: por um lado, um segmento da sociedade que se agarra a esta estereotipia, na expectativa de controlar o professor nas suas ações profissionais, na sala de aula e fora dela e, por outro, o profissional ou a instituição escolar que, através de seu poder disciplinador, reproduz em sala de aula uma lógica semelhante: a fabricação de corpos dóceis, homogeneizados (FOUCAULT, 1997). Esta lógica dualista tem sido predominante nas práticas educacionais, gerando desentendimentos entre estes atores sociais, reforçando as relações de poder dentro da escola e dificultando o diálogo entre educador e instituição e educador e educando. Nesse sentido, partindo de interesses divergentes, as relações destes personagens no espaço escolar reproduzem as redes de poder e subordinação existentes na sociedade.

Esta situação complexifica-se quando se trata do professor de arte, pois é ainda mais forte o estigma histórico que tangencia este campo e o profissional que nele atua, marcando-o como carente de criticidade e, consequentemente, como oferecendo contribuição menos relevante para o desenvolvimento da sociedade. Como resultado 
temos um profissional/docente fragilizado, com baixa auto-estima e que continuamente necessita justificar teórica e metodologicamente sua importância, criando desconfortos, ausência de pertencimento para ele e para o campo de ensino de arte.

Uma questão acompanhou-nos neste percurso pelo Espaço das Profissões: o que os desenhos e pinturas produzidos por licenciandos (futuros docentes), sem informações sobre objetivos e processos que orientaram os trabalhos, significavam para os visitantes? Que sentidos eles construíam naquela experiência de ver aqueles trabalhos? É possível que os visitantes tenham sido levados a crer que a ênfase da formação dos futuros professores está fortemente vinculada à prática do desenho e da pintura, que o requisito básico para o ingresso e continuidade num curso de Licenciatura em Artes Visuais é o domínio de técnicas orientadas por um realismo acadêmico. Por que um curso dedicado à formação de professores representa-se, ao utilizar imagens, através de pinturas e desenhos dos alunos? Como a formação e a prática docente poderiam ser apresentadas nesta situação?

Voltando às atividades propostas na sala do curso de Licenciatura presencial, algumas considerações merecem destaque. Na tentativa de interagir com os jovens visitantes, a proposta do jogo com palavras, mencionado anteriormente, teve resultados insatisfatórios, no nosso ponto de vista. Cada visitante podia escolher uma palavra e dizer algo referente a ela. Enquanto os colegas aguardavam algum tipo de interação ou respostas, criava-se uma situação de desconforto e constrangimento. Num primeiro contato com esta área de conhecimento, por que pôr a prova o jovem visitante? $\mathrm{O}$ desestímulo era visível, além de ineficaz no sentido de captar o interesse e a atenção dos possíveis futuros alunos.

Constatamos, também, a baixa freqüência de visitantes nas salas preparadas para mostrar os cursos de licenciatura em artes visuais. Uma pergunta perseguia-nos: que imaginário de docência e ensino de arte orientou a organização da mostra? Não havia, conforme observamos, pistas a respeito das motivações para tais escolhas, nem mesmo sobre a seleção de materiais expostos. Que visualidades representativas do ensino de arte poderiam construir-se através daquelas escolhas? Estaria ainda presente uma visão de ensino academicista centrada na história da arte e baseada em conceitos de "pureza" e de "livre" expressão criadora?

A tentativa de envolver os jovens na atividade interativa leva-nos ainda a outras reflexões: como as posições de sujeito docente projetam mudanças nos modos de pensar e ensinar arte na contemporaneidade? Que transformações os modos de vida atuais 
sinalizam para a formação docente? O silêncio e a ausência de interesse dos jovens visitantes talvez indiquem o descompasso entre as demandas contemporâneas, o modo de vida atual e o ensino universitário. Descompasso que também se faz notar nas salas de aula do ensino fundamental e médio, conforme já foi muitas vezes comentado. Diante dessas inquietações e constatações, finalizamos esta reflexão indicando alguns caminhos que orientam nossa maneira de ver a formação de professores.

\section{Repensando a formação de professores a partir da experiência no espaço das profissões da UFG}

Primeiramente, desejamos problematizar a crença comum de que o ato de ensinar passa simplesmente pela relação onde um ensina e outro ouve atentamente, e aprende. Não visualizamos a formação de professores de arte como um treinamento profissional para exercer esta função nas escolas. Concebemos esta formação como uma construção através da qual os professores fundamentam suas idéias e práticas sobre ensinar e aprender guiados por um comportamento ético, estético e político, que vise integrar as várias dimensões da experiência docente.

A base da ética docente a qual nos referimos está no comprometimento com a formação de subjetividades solidárias, autônomas e protagonistas de seus processos de aprendizagem. O comportamento estético que projetamos se contrapõe ao modelo de organização estrutural da escola que prioriza a construção de uma cidadania mantenedora do status quo e sustenta estratégias que permitiram descontinuidades e exclusões. Permitiram, também, o reforço às categorizações binárias tais como ciência versus magia, primitivo versus civilizado e, ainda, fecharam os olhos para a "truculência macho-positivista de teorias de tudo, tais como o sociologismo bourdivino, o cognitivismo high tech ou a psicologia evolucionária" (VIVEIROS DE CASTRO, 2007, p. 94). Propomos uma política que fomente a diversidade, a transversalidade, tornando as estruturas como fractais e optando pela multiplicidade de abordagens em detrimento do unitário e acabado.

Tentamos aqui responder às mudanças que afetaram e afetam as práticas artísticas e os modos de vida das pessoas nas últimas décadas, pois, como diz Arroyo (2007, p. 11), trata-se de um “momento desafiante porque as próprias crianças, adolescentes e jovens nos exigem que aceleremos o ritmo e tomemos o passo da realidade que eles vivenciam". Tal fenômeno apresenta-se e merece ser visto com atenção e não mais com um olhar de especificidades, de isolamento. 
Percebemos que as produções contemporâneas de arte envolvem estéticas híbridas, miscigenadas, que cruzam fronteiras, resultando em uma diversidade de sons, imagens e deslocamentos nos múltiplos territórios que ambientam e recriam nossa cultura. Desta forma, constroem-se diálogos que possibilitam espaços comuns que configuram "sociedades nômades caracterizadas pela mudança, o movimento e a flutuação constante de seus integrantes" (AGUIRRE, 2009, p. 158). São práticas onde as próprias produções estabelecem diálogos transdisciplinares:

Explicadas de outra maneira, essas miscigenações culturais e estéticas além de criar deslocamentos de fronteiras culturais, subvertem hierarquias estéticas e misturam estilos, oferecendo oportunidade para experimentações sincréticas que abrem espaço para transmutação de signos que se re-semantizam adquirindo novos significados ao serem usadas em outros contextos (MARTINS, 2008, p. 26).

Se prestarmos atenção no modo de vida dos jovens na atualidade, a incessante presença das imagens e das mídias em seu cotidiano, e, de outro lado, a forma como as licenciaturas em artes visuais - presencial e a distancia - foram representadas no espaço das profissões, vamos constatar a ausência de conexões e reflexões que considerem essas dinâmicas envolvendo a prática docente e o ensino de arte. Hoje, sabemos que “esteticamente tudo é permitido, tudo é possível e tudo está revestido de certa provocação às regras que pré-estabeleciam o que é e o que não é arte" (Arroyane, 2005, p. 47 apud MARTINS, 2008, p. 26). Sabemos, então, sobre o poder de representação dos artefatos imagéticos com os quais os jovens convivem.

Verificamos a necessidade de abordagens no ensino e na formação de professores que possibilitem a ampliação de repertórios, de maneira geral circunscritos às imagens de arte predominantemente européias, para abordagens que se estendam, incluam, valorizem e problematizem não apenas as imagens e produções que fazem parte do cotidiano dos futuros professores, mas os modos como eles se relacionam com as experiências de ver e olhar. Assim, encorajaremos uma formação docente que pense o ensino de arte através de "possibilidades pedagógicas para afrontar criticamente a estreiteza da estereotipante redundância temática, ideológica e estética da cultura de massa" (AGUIRRE, 2009, p. 166).

Precisamos desenvolver atitudes e concepções que privilegiem a construção de um pensamento crítico, abrindo espaço para que os estudantes possam experimentar, refletir e (des) construir posicionamentos sobre suas realidades através de processos nos quais o campo de estudo aborde “... todos os artefatos geradores de experiência estética, 
provenham eles das belas artes, das artes populares ou da denominada cultura visual" (AGUIRRE, 2009, p. 169).

Neste cenário, como mostrar a um aluno adolescente - faixa etária da maioria dos visitantes - que ensinar arte é um processo sócio-cultural complexo? Que imagens sobre os cursos de licenciatura esses adolescentes levaram consigo?

Como comentamos anteriormente, professores de arte, em geral, são vistos, de maneira estereotipada, como aqueles que fazem cartazes e bandeirolas para a festa junina, que ensaiam a peça de teatro para celebrar o dia das mães e que usam o tempo da escola com atividades de desenhar e colorir. Essa representação, reforçada naqueles ambientes, leva-nos a concordar com a observação de Ivor Goodson (2007) ao dizer que "estão transformando o ensino numa profissão atrativa somente para os submissos e dóceis e, inversamente, não atraente para os criativos e competentes" (p. 39).

Se somos movidos por curiosidades, aspirações, crenças e desejos, por que terminamos a visita aos espaços dedicados às licenciaturas sem experimentar algum sentimento de provocação ou mobilização para a prática docente?

Vale a pena nos deter, para concluir, em parte dos resultados de uma pesquisa feita pela Fundação Victor Civita, em 2009, com 1.501 alunos do terceiro ano, de 18 escolas públicas e privadas de cinco regiões do Brasil. O intuito era investigar a atratividade de jovens pela carreira docente ${ }^{14}$. A pesquisa revelou resultados preocupantes: a profissão docente não é considerada uma opção atraente pelos estudantes do Ensino Médio. Somente $2 \%$ desses alunos têm a pedagogia ou alguma licenciatura como opção principal no vestibular. Ainda de acordo com a pesquisa, um terço dos jovens entrevistados pensou em ser professor, mas desistiu. Segundo os estudantes, os motivos que os fizeram desinteressar pela carreira docente são: desvalorização social da profissão, baixa remuneração e más condições de trabalho.

Estes resultados fazem-nos retomar a reflexão sobre as licenciaturas da FAV da UFG, reforçando algumas questões: como os cursos podem apresentar-se para aqueles que desejam ingressar na universidade? Que ênfases as licenciaturas da FAV podem oferecer para a formação de futuros professores? Quem são - como se caracterizam - os alunos que procuram as licenciaturas?

\footnotetext{
${ }^{14}$ Revista Nova Escola, edição especial “Por que tão poucos querem ser professor?", fev. 2010.
} 


\section{Considerações finais}

A proposta de escolher uma palavra e dissertar sobre ela significou, para nós, um jogo duplo. Se, por um lado, desestimulou nossa participação no Espaço das Profissões, por outro, levou-nos a questionar sobre como expor e representar as licenciaturas sob estas circunstâncias.

As representações que esta experiência deflagrou em nós, mestrandos, foram contraditórias, mas "de fato, representações estimulam interpretações que, por sua vez, carregam repertórios de quem as representa" (MARTINS; PEREIRA; VALENÇA, 2008, p. 249). Talvez tenhamos que compreender, com mais profundidade, quais são nossas representações das licenciaturas, como as construímos e como as tornaríamos públicas.

Imaginamos ser necessária uma abordagem crítica e questionadora sobre as imagens a serem apresentadas nas salas e no telão. Tal abordagem poderia, através de perguntas, instigar os jovens visitantes a interagir, por exemplo, com imagens de publicidade e das mídias contemporâneas, com as quais muitos deles se identificam, empoderando-os como sujeitos "para que se tornem capazes de perceber narrativas eticamente desonestas, recheadas de signos de intolerância, sexismo, homofobia, racismo, desigualdade e opressão", chamando a atenção para o ensino de arte que sonhamos tornar realidade (MARTINS; PEREIRA; VALENÇA, 2008, p. 250).

Apresentar a ideia de que licenciandos em artes visuais também estudam e trabalham com imagens de diversas naturezas (publicidade, ficção, filme, HQ etc.) e resistir à posição de que o arte-educador apenas ensina técnicas manuais seria uma oportunidade para abrir espaços de reflexão e diálogo entre e com os visitantes. Nossas observações não desconsideram o fato de que a proposta do Espaço das Profissões é desafiante e complexa. Porém, formas alternativas de apresentar e representar cada curso precisam ser pensadas, criadas e experimentadas. Trabalhar com visualidades contemporâneas, o que pressupõe abordagens transdisciplinares e trânsitos entre diferentes campos do saber, seria uma maneira de empoderar os visitantes agenciamentos críticos frente aos discursos, estratégias de persuasão e possibilidades de manipulação do mundo das imagens ajudando-os a desconstruir e (re) construir concepções de mundo, tempo e espaço.

\section{Referências}

AGUIRRE, I manol. Imaginando um futuro para a educação artística. In: MARTINS, Raimundo; TOURINHO, Irene (Orgs.). Educação da cultura visual: narrativas de ensino e pesquisa. Santa Maria: Editora da UFSM, 2009. 
ARROYO, Miguel. I magens quebradas: trajetórias e tempos de alunos e mestres. Petrópolis: Vozes, 2007.

FOUCAULT, Michel. Vigiar e Punir: história das violências nas prisões. Trad. Raquel Ramalhete. Petrópolis: Vozes, 1997.

GOODSON, Ivor. Pessoas solitárias: a luta pelo significado privado e o propósito público. In: MARTINS, Raimundo; TOURINHO, Irene (Orgs.). Políticas do conhecimento: vida e trabalho docente entre saberes e instituições. Goiânia: Cegraf, 2007 (Coleção

Desenredos, 2), pp. 13 - 48.

HALL, Stuart. Quem precisa da identidade? In: SILVA, Tomaz Tadeu da

(Org.). I dentidade e diferença: a perspectiva dos Estudos Culturais. Petrópolis: Vozes, 2000.

MARTINS, Raimundo. Das belas artes à cultura visual: enfoques e deslocamentos. In: (Org.). Visualidade e educação. Goiânia: FUNAPE, 2008 (Coleção Desenredos, 3). Parte I - Temporalidades e posicionamentos na cultura visual no ensino de artes no Brasil e nos Estados Unidos - leituras regionais, pp. 25 - 36.

MARTINS, Raimundo; PEREIRA, Alexandre; VALENÇA, Kelly. Um olhar 'formatado'.

Visualidades: Revista do Programa de Mestrado em Cultura Visual. Goiânia, v. 6, n. 1 e 2, pp. 243 - 254, 2009. ISSN 1679 - 6748.

MARTINS, Raimundo; TOURINHO, Irene. Entre contingências e experiências vividas... Propostas para pensar um ensino crítico em artes visuais. Visualidades: Revista do Programa de Mestrado em Cultura Visual. Goiânia: UFG, v. 3, n. 1, pp. 86-111, 2005.

REVISTA NOVA ESCOLA, Edição Especial "Porque tão poucos querem ser professor". São Paulo: Abril, fev. 2010. [relatório preliminar da pesquisa em:

<http://revistaescola. abril.com. br/pdf/relatorio-final-atratividade-carreira-docente. pdf $>$ ]

VIVEIROS DE CASTRO, Eduardo. Filiação intensiva e aliança demoníaca. Novos

Estudos 77, [s. I.], 2007, pp. 91 - 126. 